\title{
Erratum to: Towards an unbiased metabolic profiling of protozoan parasites: optimisation of a Leishmania sampling protocol for HILIC-orbitrap analysis
}

\author{
Ruben t'Kindt • Andris Jankevics • Richard A. Scheltema • Liang Zheng • \\ David G. Watson • Jean-Claude Dujardin • Rainer Breitling • Graham H. Coombs • \\ Saskia Decuypere
}

Published online: 11 March 2011

(C) Springer-Verlag 2011

\section{Erratum to: Anal Bioanal Chem \\ DOI 10.1007/s00216-010-4139-0}

Unfortunately, the references in the following sentence in the introduction were incorrect.

"De Souza et al. [9, 10] have described rapid (seconds) quenching of Leishmania cultures to $0{ }^{\circ} \mathrm{C}$ using a dry iceethanol bath. They reported that this method quenches metabolism of Leishmania reliably and reproducibly."

The citations $[9,10]$ should be replaced by the following 2 references:

The online version of the original article can be found at http://dx.doi. org/10.1007/s00216-010-4139-0.

R. t'Kindt · J.-C. Dujardin $(\bowtie) \cdot$ S. Decuypere

Department of Parasitology, Unit of Molecular Parasitology,

Institute of Tropical Medicine,

2000 Antwerp, Belgium

e-mail: JCDujardin@itg.be

\section{A. Jankevics $\cdot$ R. A. Scheltema $\cdot$ R. Breitling}

Groningen Bioinformatics Centre, Groningen Biomolecular

Sciences and Biotechnology Institute, University of Groningen,

Kerklaan 30,

9751 NN Haren, The Netherlands

A. Jankevics $\cdot$ R. Breitling

Faculty of Biomedical and Life Sciences, University of Glasgow,

Glasgow G12 8QQ, UK

R. t'Kindt $\cdot$ L. Zheng $\cdot$ D. G. Watson $\cdot$ G. H. Coombs

Strathclyde Institute of Pharmacy and Biomedical Sciences,

University of Strathclyde,

Taylor Street,

Glasgow G40NR, UK
De Souza DP, Saunders EC, McConville MJ, and Likic VA (2006) Bioinformatics 22:1391-1396. (reference [36] of the manuscript)

Saunders EC, De Souza DP, Naderer T, Sernee MF, Ralton JE, Doyle MA, MacRae JI, Chambers JL, Heng J, Nahid A, Likic VA, and McConville MJ (2010) Parasitology 137:1303-13 (reference not listed in the manuscript)

Furthermore, we should like to make the following acknowledgement:

We are grateful to Prof. Malcolm McConville and his team at the Bio21 Institute at the University of Melbourne for their advice and guidance regarding the Leishmania metabolome extraction protocol. 